\title{
AS ORIGENS DOS NOMES DE PESSOAS*
}

\author{
Patricia de Jesus Carvalhinhos ${ }^{* *}$
}

Resumo. Usar a língua e sua significação simbólica para apropriar-se do mundo tem sido uma constante desde os primórdios humanos. Analisar as origens dos nomes próprios não é diletantismo, mas sim uma forma séria de resgatar fatos sociais, culturais e religiosos, entre outros; fatos aparentemente perdidos, mas devidamente registrados nos fragmentos de significação intactos nos nomes. Este artigo se propõe a mostrar como isto é possível e quais as principais vertentes teóricas; a Onomástica, seja em sua vertente toponímica ou antroponímica, se vale da língua para detectar fatos e motivos superpostos durante os séculos, proporcionando um resgate de memória coletiva.

Palavras-chave: Onomástica; antroponímia; nome próprio; lexicologia.

Abstract. Using language and its symbolical signification to rule the world has been an invariable practice since the genesis. Analysing person's names, therefore, should be considered among other things a serious way of recovering social, cultural and religious facts. These facts apparentely lost are duly registered in the untouched fragments of signification within a person's name. As this paper intends to show, the Onomastic Science, through the sub-areas of Toponimy and Anthroponimy, uses language to rescue causes and facts overlaid during centuries of human existence, and it represents a real cultural recovery of collective memory.

Key-words: Onomastics; Anthroponimy; person's names; lexicology.

\section{INTRODUÇÃO}

$\mathrm{Na}$ esteira dos quinhentos anos do descobrimento do Brasil vários temas têm sido abordados. Contudo, uma lacuna poderá ser suprida com este breve artigo: as origens dos nomes de pessoas, um fator tão corriqueiro no dia-a-dia que as pessoas não dão atenção às dimensões mais profundas deste fenômeno, hoje em dia, muito mais ideológico que identificador, como foi no passado. Tendo em vista que o sistema onomástico brasileiro tem grande influência do sistema onomástico português, este estudo justifica-se.

Seja como integrante étnico ou como doador ideológico, o português contribuiu para a formação do Brasil atual, juntamente com outros grupos (estratos indígenas e

* Publicado originalmente na Revista Álvares Penteado, v.2, n5, dez. 2000, pp. 165 a 177

** Professora Doutora do Departamento de Letras Clássicas e Vernáculas, ministra aulas de Toponímia Geral de do Brasil (Área de Línguas Indígenas do Brasil, subárea Toponímia) na Faculdade de Filosofia, Letras e Ciências Humanas da USP desde agosto de 2005. 
africanos); muitas vezes a ideologia européia herdada por nós se encontra tão enraizada que é quase impossível discernir o que é realmente nacional do que é herança colonial. Neste sentido, o sistema antroponímico brasileiro tem suas raízes fincadas em Portugal, não no país atual, mas no Portugal navegador do século XVI. Portanto, muitos dos nomes adotados ainda hoje são extremamente antigos, apesar de sua aparência de modernidade. Nomes como Pedro, atualmente na moda (em autonomia ou em composição), são tão antigos quanto o Novo Testamento; de acordo com Dick (1990), Pedro é um nome perene. A grande diferença é que no começo dos tempos, como veremos adiante, o nome era conotativo, isto é, sua carga significativa era perfeitamente decodificável. Atualmente, o nome é dado principalmente em virtude de sua beleza sonora.

Passemos, agora, a definir exatamente o que é Antroponímia, o ramo da ciência dos nomes (Onomástica) que se ocupa dos nomes próprios de pessoa.

\section{A Antroponímia: principais questões e perspectivas}

A expressão Antroponímia, em língua portuguesa, data de 1887 e é do filólogo português Leite de Vasconcelos, que a utilizou em sua Revista Lusitana. Assim como sua linguagem, a definição de Antroponímia por ele concebida é bastante clara, e diríamos simples: “(...) estudo dos nomes individuais, com o dos sobrenomes $e$ apelidos; (...)" (Vasconcelos, 1931:03). Apesar de ser algo tão cotidiano e comum, fora dos meios acadêmicos a importância do antropônimo não é considerada: o nome próprio tem como função registrar atitudes e posturas sociais de um povo, suas crenças, profissões, região de origem, entre outros aspectos; estes fatores, por si, revelam a dimensão da necessidade de pesquisas neste campo. Hoje, em termos de motivação, os nomes próprios são mais uma questão de fé e de influência televisiva (a tendência da grande massa da população brasileira é nomear suas crianças com o nome do (a) herói/heroína da novela que está sendo exibida com grande sucesso; em homenagem a seu santo ou santa de devoção, ou em agradecimento por uma graça alcançada).

Em tempos remotos, o nome próprio cumpria a função significativa, isto é, sua função semântica estava assegurada: o indivíduo não era apenas designado por seu nome, como recebia toda sua carga conotativa. Um exemplo que ilustra esta questão está no nome Cícero, proveniente do nome latino Cicero, derivado de cicer,-eris, "grão 
de bico" (Faria, 1988:105). No exemplo citado primeiramente o nome teria sido utilizado como alcunha, pejorativamente (em provável alusão a um sinal grande no rosto, semelhante a um grão de bico); como a língua é naturalmente dinâmica, o nome é rapidamente esvaziado de seu real sentido etimológico restando apenas um invólucro, uma forma opaca que oculta o verdadeiro significado original do nome.

Muitos autores têm estudado a questão do nome próprio, entre eles Ullmann, Mill e Dauzat. Por exemplo, J. Stuart Mill sugeriu algumas diretrizes para a conceituação de nome próprio e qual sua função semântica. Diferentemente do que acontecia anteriormente (nome com função conotativa), Mill sugeriu que o nome próprio possui uma função distintiva, não significativa. Em sua concepção, os nomes próprios não conotam, pois nenhum atributo do indivíduo nomeado lhes é conferido:

"sempre que os nomes dados aos objetos comunicam qualquer informação, isto é, sempre que têm qualquer significado, esse significado não reside no que designam, mas no que conotam. Os únicos nomes de objetos que nada conotam são os nomes próprios; e estes não têm, estritamente falando, nenhuma significação.”(Mill apud Ullmann, 1964:154)

Se hoje as sociedades ocidentais ${ }^{1}$ apresentam esse fenômeno do esvaziamento semântico nos nomes próprios de pessoas, nestas mesmas sociedades durante a Antiguidade os nomes não eram atribuídos por tradição ou gosto, mas efetivamente havia um motivo ou uma motivação ao fazê-lo, fosse por atributos físicos ou morais que se quisesse imprimir no indivíduo nomeado, fosse por devoção ou pela crença que um nome sagrado ou ligado ao sagrado traria sorte ao portador do mesmo. As motivações que emergem hoje dos antropônimos pertencentes ao sistema onomástico brasileiro são antiquiíssimas, e tais motivos (atualmente não conotativos) podem ser de diversas ordens, como profissões, local de origem, religiosidade, entre outros. Um autor que definiu algumas causas que haveriam originado vários nomes é Guérios (1973), para quem os motivos que orientavam a criação de novos antropônimos tornavam-nos aptos

\footnotetext{
${ }^{1}$ O nome próprio de pessoa é motivado em sociedades orientais, por exemplo, além de o ser em várias sociedades indígenas brasileiras.
} 
a funcionar como um espelho da cultura, a refletir as manifestações culturais de todo um povo. Guérios cita quatro causas, apontadas a seguir:

- Influências históricas, políticas e religiosas: Desde os povos mais antigos (gregos, hebreus e germânicos entre outros vários), os pais buscavam a proteção divina para seus filhos. Com o advento do cristianismo, a tendência de dar nomes divinos prosseguiu, agora sob a forma de homenagem aos santos e santas da Igreja Católica. Quanto à motivação política, reflete-se nesta escolha o entusiasmo e admiração, por parte dos pais, a personagens políticas em evidência num determinado momento - e sua relação com o poder. Entre os nomes históricos o autor cita Romeu ("peregrino que ia a Roma receber a indulgência do Papa") e Percival, clara referência ao bravo cavaleiro dA demanda do Santo Graal.

- Circunstâncias, lugar e tempo de nascimento: particularidades físicas ou qualidades morais. Respectivamente, citamos Agripa ou Agripino, nome dado à "criança que, no parto anormal, apresenta primeiro os pés"; Libânio, "nascido no Monte Líbano"; Lucius/Lucia, "o que ou a que nasceu à luz do dia, ou ao romper d'alva"; Aurelius/Aurelianus, "da cor do ouro", e Bruno, "o de olhos e cabelos escuros"; ilustrando o último item, Astolfo, "impetuoso, violento como o lobo".

- Nomes relativos a profissões, como Cavalcante (cavaleiro) e Jorge (agricultor).

- Nomes curiosos ou excêntricos, de formação atípica, e difícil compreensão: Edeluz ("espírito de luz") e Damores, entre muitos outros. Dauzat propõe mais dois elementos nitidamente presentes no ato de nomeação: o fato conservador, que leva à perpetuação de certos nomes de família (isto é, determinado nome passaria a ser "tradição de família"), e também as influências da moda, já citadas anteriormente, impostas principalmente pelos meios de comunicação em massa: é o caso da enorme quantidade de antropônimos (muito antigos) como Rodrigo, Marcos, Daniela e Cláudia, pequena amostragem dos nomes próprios mais adotados atualmente por influência da televisão ${ }^{2}$, conforme pesquisas que vem sendo realizadas.

\section{As categorias antroponímicas: as categorias de nomes de pessoas}

\footnotetext{
2 A cada ano, em levantamentos atualizados realizados por alunos de graduação (regularmente matriculados na disciplina Toponímia Geral e do Brasil, oferecida na USP), vão ficando claras novas influências da mídia (outros nomes na moda), sobretudo no que se refere a personagens de novelas, além de homenagens a esportistas.
} 
Como já foi mencionado, o nome próprio tem como função principal diferenciar as pessoas entre si, o que não significa simplicidade: o assunto é complexo, iniciando pelas várias acepções de nome. Leite de Vasconcelos (1928:8), acertadamente, registra esta complexidade como um fato corrente na língua portuguesa: "Se é corrente o expressarmos uma mesma idéia por várias palavras (Onomasiologia) ${ }^{3}$, também não é raro traduzirmos por uma mesma palavra várias idéias (Sematologia) (...)”. Quando banalmente aplicamos a palavra nome a um indivíduo, não especificamos em qual acepção a estamos utilizando. Basicamente, há quatro definições para nome:

- Nome próprio ou individual. É o nome dado no momento do batismo, ou do nascimento da pessoa. Tomemos por exemplo o nome do autor em questão, Leite de Vasconcelos, válido para todas as aplicações. Nesta acepção, o nome individual é José.

- Nome completo. Trata-se do conjunto das designações pessoais: José Leite de Vasconcelos.

- Qualquer um de seus elementos. Ao inquirir o nome do autor, diretamente a ele ou a outra pessoa, obteríamos respostas variadas: José, Vasconcelos, ou ainda Leite de Vasconcelos. Apesar das diferentes categorias em que estão inseridos, todos são designados, simplesmente, por nomes.

- Alcunha ou apodo. Tratamento informal, de caráter passageiro (apodo) ou permanente (alcunha). É considerado nome a partir do momento que individualiza e designa determinada pessoa. Uma alcunha muito comum no Brasil, para o nome José, é a forma reduzida Zé.

Cumpre-nos informar que, vulgarmente, há confusão generalizada entre as pessoas no que se refere a categorias de nomes. O nome próprio, ou de batismo, é a única categoria que escapa ilesa dessa babel: popularmente, sobrenome é tudo aquilo que não pode ser considerado nome de batismo; apelido é erroneamente tomado na concepção de alcunha ou apodo. Tal confusão pode ocorrer justamente pela

\footnotetext{
${ }^{3}$ Com relação à Onomasiologia, devemos registrar que desde os fins do século XIX e princípio do século $\mathrm{XX}$, quando Leite de Vasconcelos realizava seus estudos, o conceito de Onomasiologia mudou muito, assim como ocorreu com a Lingüística Geral, desde Saussure.
} 
complexidade do assunto, e pela maneira que a definição de cada categoria está semanticamente unida à outra; além disso, o próprio Leite de Vasconcelos afirma que essa confusão terminológica já acontecia em Portugal desde há muito tempo ${ }^{4}$. Cabe aqui, à guisa de elucidação, a breve explanação de cada uma das categorias, nas palavras do próprio Leite de Vasconcelos:

- Nome próprio ou individual: nome de batismo.

- Sobrenome: "é um patronímico, nome de pessoa, expressão religiosa ou outra, que se junta ao nome individual’. O exemplo que esclarece o item é o nome de um santo, São Francisco Xavier, no qual Xavier é sobrenome.

- Alcunha: "designação acrescentada ao nome normal do indivíduo por outros, que neste observam certa particularidade ou certa qualidade física ou moral digna de nota, ordinariamente jocosa ou insultuosa, mas também séria."

- Apodo: equivale à alcunha, porém seu caráter é passageiro, enquanto o da alcunha é, muitas vezes, definitivo, a ponto de passar de geração a geração (convertendo-se, pois o filho de um indivíduo que recebeu a alcunha não a terá como alcunha, uma vez que não possui os mesmos atributos de seu pai. Os semas da alcunha se perdem; tornando-a opaca).

- Patronímico: "representa um genitivo derivado do nome do pai, o qual na Idade Média indicava filiação.” Assim, Vaz é o patronímico que designava alguém como

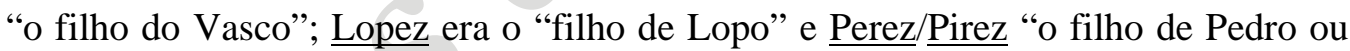
Pero". Analogamente, há muitos outros casos de patronímicos que sobrevivem até hoje, embora consolidados como apelidos de família e esvaziados do sentido primeiro, expressar filiação.

4

Ainda na Introdução de sua obra Antroponímia Portuguesa o autor menciona as várias definições e confusões terminológicas entre definições propostas por vários tratadistas, assim como diferentes significações para o mesmo conceito em várias partes do país: "Mas com relação ao passado, $e$ ainda não raro com relação ao presente, as cousas não são tão simples como ficam expostas: houve muitos modos de as compreender (...)". E mais adiante, completa: "A antiga confusão permanece pois agora, ainda que a distinção mais usual, sobretudo no Sul, é a que acima ficou indicada, e se adopta na presente obra: sobrenome, segundo nome, junto individualmente ao nome próprio; apelido, nome de família." (Op. Cit., 1928:12-15). 
Seguir passo a passo o trabalho realizado por Leite de Vasconcelos não é possível, primeiro porque nossa intenção está longe de fazer uma retrospectiva do que já é fato; outro motivo é a distância temporal, espacial e sobretudo cultural que separa nossa realidade atual da realidade do início do século. Nesta abordagem, procuramos remeter exemplos de antropônimos à realidade atual brasileira, cuja cultura contém influências não só portuguesas, mas também indígenas, africanas e, com o advento das telecomunicações, americanas (visto o jugo imperialista que nos mantém culturalmente atados aos Estados Unidos da América, similarmente ao que ocorre com os demais países do Terceiro Mundo). Explanaremos, agora, cada uma das categorias de nome próprio, implicadas em suas inter-relações.

\subsection{O nome próprio.}

Basicamente, o nome próprio pode originar-se de fontes históricas, bíblicas ou modernas. Nos nomes de língua portuguesa, a origem liga-se à própria história da língua. Os nomes medievais (período das Navegações) provêm, naturalmente, dos nomes adotados pelos povos que habitavam a Península, lusitanos e hispanos, dominados e influenciados pelos fenícios, gregos e em seguida pelos romanos, que, por sua vez, cederam o território aos povos germânicos (já latinizados) e posteriormente aos árabes.

Os romanos possuíam um sistema de nomeação tríplice, isto é, utilizavam três nomes (triplex nomen); contudo, entre os séculos V e VIII, quando o cristianismo já mostrava sua força enquanto motivo para nomear, esse sistema do triplex nomen encontrava-se tão desorganizado quanto o poder romano na Península. Os nomes, então, eram mais simples, mesmo por influência germânica: somente um único nome. Exemplos de origens variadas de nomes usados na referida época oferece-nos uma pequena idéia da confusão de raças: havia os de proveniência latina (Paulus, Tyberius, Amanda, Donata), grega ( $\underline{\text { Andreas, }}$ de $\Lambda v \delta \rho \varepsilon \alpha \varsigma$, Satirio, de $\Sigma \alpha \tau u \rho \iota \omega v)$ e germânica (Sisenandus, de sis e nanths). Mais tarde, dos fins da idade média até o século XIX, tornam-se mais freqüentes os nomes de santos e santas da Igreja Católica e nomes hebreus, provenientes da Bíblia. 
Nessa época mais recente as motivações religiosas obedeciam a certos critérios: nomeação pelo dia do nascimento, por devoção ou por apadrinhamento. O primeiro critério baseava-se no calendário (efemérides): para cada dia havia um santo ou santa, e, nascida a criança, verificava-se qual era o santo do dia e assim estava denominada, mesmo que se mudasse a terminação do nome. O segundo não necessita de esclarecimentos; contudo, o terceiro critério mostra-se muito interessante: as pessoas criam que, ao dar o nome de uma entidade divina a uma criança, no ato do batismo havia uma espécie de transubstanciação, na qual o santo ou entidade "penetrava" no corpo carnal do padrinho para oferecer suas graças ao afilhado.

Nos fins do século XIX e princípio do XX também se verifica a presença de nomes com influências mitológicas e literárias. Apenas para citar poucos exemplos temos, respectivamente, Aurora (originariamente, deusa da manhã para os romanos) e


medieval A demanda do Santo Graal e Eurico, personagem do romance de Herculano, Eurico, o presbítero.

Hoje, como já foi explanado na Introdução, a televisão é um poderoso veículo de comunicação. Mesmo sem a realização de um estudo sobre o assunto, é possível afirmar, apenas pela observação empírica, que cada vez mais há acesso a nomes importados, oriundos de outras sociedades (como Yuri, do russo; e Stèphanie, por influência da princesa de Mônaco), nomes de atores e cantores famosos, resgate de nomes indígenas brasileiros (Jaci, por exemplo) e mesmo a invenção de nomes, compostos por uma parte do nome do pai e outra do da mãe (pai Eli, mãe Mara; gêmeas Elimar e $\underline{\text { Mareli). }}$

\subsection{O sobrenome.}

2.2.a. Sobrenomes derivados de nomes de pessoas.

Considerado um complemento do nome individual, o sobrenome existe desde a Antigüidade. Nesta época, o sobrenome era usado para relacionar, em narrações e documentos, um determinado indivíduo a seu pai. Surgiu assim o patronímico, genitivo 
do nome paterno agregado, na maior parte das vezes, em posposição ao nome individual. Passando por todas as formas do genitivo latino (-i, -e; -is, -es; -onis, -oni; anis, -ani), as mais comuns foram as formas em $-a z,-i z,-o z$ e $-u z$. Por exemplo, Fernandes, hoje apelido de família esvaziado de seus semas, era um patronímico transparente na idade média, significando "filho de Fernando". Assim, vários apelidos de família atuais têm sua origem em patronímicos, como já explicamos acima: $\underline{\text { Vaz, }}$ $\underline{\text { Álvares }}, \underline{\text { Peres/Pires, }} \underline{\text { Dias, }}$ Domingos, $\underline{\text { Henriques, }}$, entre muitos outros.

Não apenas os patronímicos expressavam filiação. O substantivo latino filius era utilizado, assim como os árabes empregavam iben. Hoje há vestígios deste hábito de nomeação quando alguém se chama, por exemplo, Cláudio Braga Filho, filho de Cláudio Braga, assim como o uso de Júnior (do adjetivo junior, significando pessoa mais jovem, em oposição a senior). Em outras línguas modernas o nome contém uma partícula que designa "filho de". No caso do inglês, houve o esvaziamento semântico como nos patronímicos em língua portuguesa, e encontramos formas como Peterson, Edson, Wilson (filho de Peter, Ed e William, respectivamente), entre outras. Leite de Vasconcelos cita casos nos quais o nome individual do pai ou da mãe era usado como sobrenome dos filhos: José Maria e Antonio Maria, filhos de Maria José; Manoel Inês, filho de Inês; Maria Jacinta, filha de Jacinta; Sebastião Onofre, filho de Onofre, Teresa Caetana, filha de Caetano ${ }^{5}$.

Também um sobrenome do pai ou da mãe era utilizado como sobrenome do filho, a exemplo de Antonio Afonso de Andrade, filho de Antonio Afonso; Antonio Luís Delgado, filho de Domingo Luís; Antonio Thomás de Miranda, filho de Francisco Thomás. Estes nomes foram retirados de documentos do século XVII, mas o autor cita nomes nestes moldes já presentes em documentos do século XIII. Os sobrenomes podiam homenagear, inclusive, algum amigo ou familiar, como avós, padrinhos, tios. Às vezes, o sobrenome do filho estava tematicamente relacionado ao nome ou sobrenome dos pais, como uma Maria Regina, filha de João dos Reis, ambos sobrenomes baseados no reg- latino.

\footnotetext{
${ }^{5}$ Estes nomes fazem parte de estudos de campo, realizados por Leite de Vasconcelos em Lisboa e outras localidades.
} 
Esta modalidade de sobrenome sobre a qual dissertaremos agora é de suma importância para a análise de antropônimos a ser realizada em artigo subseqüente ${ }^{6}$, pois é uma forma de nomeação extremamente popular: uma perífrase em que entra o nome de algum familiar para designar o indivíduo por relação a outra pessoa. Acreditamos que este fato se dê em pequenas comunidades campesinas como um motivo cultural, além de prático: evita a confusão de identidade e indica uma relação de posse. Embora um marido possa ser designado com uma perífrase do nome da esposa (José Carvalho da Ludovina, casado com uma Ludovina), o mais freqüente é encontrar filhas e esposas assim designadas em relação de dependência do nome do pai/marido. Seguem alguns exemplos: a Maria do Bernardo (filha de Bernardo), a Gertrudes do Domingos (mulher de Domingos), a Ana do João (a mulher de João), e assim por diante. Note-se que a designação popular faz-se mais transparente pelo uso do artigo antes do nome individual.

A exemplo do que ocorre com o nome individual, outrora também o sobrenome não possuía, necessariamente, relação com o nome dos pais ou da família: poderiam ser motivados por fatos históricos, literários ou políticos. Mencionaremos um único sobrenome que ilustra esta afirmação: em um lugar chamado Nisa, Portugal, há registro de muitas pessoas com sobrenome Denis ou Dinis, por ter sido D. Dinis seu fundador.

\section{2.b. Sobrenomes de motivação religiosa.}

Apenas a partir do século XVI começam a surgir, com maior freqüência, sobrenomes com motivos religiosos. Antes desta época, sua utilização era quase um privilégio de frades e freiras que necessitavam trocar o sobrenome ou apelido "mundano" por um religioso, mais adequado à vida monástica.

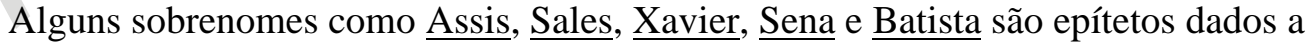
alguns santos. O exemplo mais conhecido popularmente é de São João, que recebeu o epíteto o batista após haver batizado Jesus no rio Jordão. Por este motivo alguns

${ }^{6}$ Referimo-nos ao artigo publicado em 2002 na Revista Álvares Penteado, que é uma parte prática aplicada dos conceitos aqui referidos; pretendemos republicar também esse artigo por meio digital. Cf. referência completa nas Referências bibliográficas. 
sobrenomes não se dissociavam, anteriormente, de certos nomes individuais (é o caso de

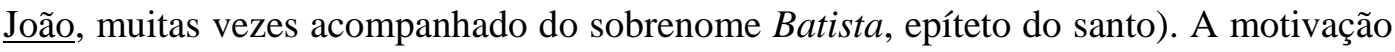
para o sobrenome religioso é exatamente igual à do nome próprio: pode ser pelo dia do nascimento, por devoção particular dos pais ou ainda por apadrinhamento.

\subsection{O apelido de família.}

As motivações dos apelidos de família podem ser exatamente iguais às dos nomes individuais e sobrenomes: inclusive quanto à forma, muitos apelidos provêm de nomes próprios e sobrenomes. Uma das causas é o próprio esvaziamento semântico do sobrenome (principalmente quando se trata de um patronímico). Por este motivo, não repetiremos aqui o que já foi explanado acima, nas categorias nome individual e sobrenome, sobre sua proveniência de nomes de pessoas, religião, literatura. Trataremos, pois, dos apelidos provenientes de topônimos e de alcunhas.

2.3.a. Apelidos de família originados em topônimos.

$\mathrm{Na}$ origem, as alcunhas eram utilizadas para designar determinada pessoa proveniente de uma região, fato ocasionado pela própria desorganização no sistema de nomeação. Era adicionada então, ao nome do indivíduo, uma alcunha indicativa da região de origem. Exemplificativamente, temos João, o Beira-Alta, assim designado por nascer neste local. Com o passar do tempo e sucessão de gerações, perde-se a referência do nome de lugar como procedência do indivíduo e a alcunha consolida-se como apelido, passando de pai a filho, sem o artigo. Alguns exemplos de topônimos utilizados, até hoje, como apelidos: $\underline{\text { Abreu}}$, $\underline{\text { Azevedo }}$, Barbosa, Barros, Barroso, Coutinho, Figueiredo, Freitas, Lago, Magalhães, Matos, Palma, Pimentel, Ramos, Resende e muitos outros, freqüentes também no Brasil.

Também de nomes de rios alguns apelidos foram designados. Neste caso, em que a importância do rio era maior que a da aldeia (ou comunidade), o uso da alcunha relacionando o indivíduo ao curso d'água permite maior transparência que se fosse feita a relação a uma localidade desconhecida em geral. Apesar de vir da literatura espanhola, este é um bom exemplo para ilustrar a questão do nome designado por uma alcunha 
referente a um rio: no romance picaresco Lazarillo de Tormes, de um autor anônimo, a personagem-título assim é denominada por haver nascido às margens do rio Tormes.

2.3.b. Apelidos de família originados em alcunhas.

As alcunhas empregadas em pessoas podem ter origem em vários motivos, como já dissemos anteriormente. Tais motivos relacionam-se ao indivíduo por vários fatores, como: mês e condição de nascimento, idade ou fases da vida; profissão; qualidades e ou atributos físicos ou morais; e ainda vestuário, hábitos e idéias mágicas. Citaremos alguns exemplos.

- Mês e condição de nascimento: Alvaro Gonçalvez Mayo, Inês Janeiro; Fernão Furtado (Furtado refere-se a filho ilegítimo).

- Idade ou fases da vida: a oposição mais comum é o novolo velho, aliás, fato muito comum na toponímia portuguesa e brasileira. Plínio, o Velho, e Plínio, o Jovem; assim eram conhecidos dois escritores romanos, Caio Plínio Segundo (o Velho), 23-79 d.C., e seu sobrinho Caio Plínio Cecílio Segundo (o Jovem), 62114 d.C.

- Profissão: tanto as alcunhas que indicam posição social (ei/Reis, $\underline{\text { Infante) }}$ como as que realmente indicam ocupação profissional encontram-se nesta categoria: Marinheiro, Alfaiate, Carpinteiro, Estudante, Mestre, Caçador, Moleiro, Monteiro.

- Qualidade física/moral: $\underline{\text { Branco, }} \underline{\text { Longo, }} \underline{\text { Pequeno, }} \underline{\text { Alvo, }}$ Gordo, $\underline{\text { Bravo }}, \underline{\text { Amado }}$ (como no nome do escritor baiano Jorge Amado), Pestana.

- Fauna e flora: A princípio, por comparação a eles o indivíduo recebia a alcunha, por uma qualidade marcante (Lobo, $\underline{\text { Raposa }}, \underline{\text { Carneiro, }} \underline{\text { Aranha, }} \underline{\text { Barata, }}$ $\underline{\text { Bezerra, }} \underline{\text { Cavalo, }}$ Leitão, Pardal; alcunhas vegetais: $\underline{\text { Botelho, }}$ Carrasco, $\underline{\text { Castanha, }}$

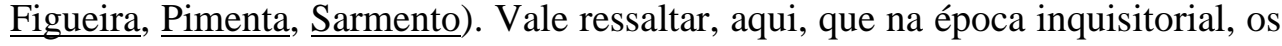
judeus que viviam na Península Ibérica convertiam-se para ficar, mudavam-se ou morriam. Na inquisição moderna, muito mais rigorosa que a medieval, os judeus conversos (cristãos novos) deveriam provar, com mudança total de hábitos e postura social, que realmente aderiram à religião católica. Sabemos hoje que a mudança era, na maior parte das vezes, externa, e a adoção de um 
nome na própria língua local garantia uma aparência de seriedade à conversão.

Adotavam, grande parte das vezes, alcunhas de animais e plantas.

\section{O esvaziamento semântico: causas e resultados}

Como já foi brevemente exposto na Introdução deste ensaio, para a compreensão global de nossa proposição faz-se necessário o estudo de alguns fatores lingüísticos presentes no fenômeno de mudança de categoria dos nomes.

$\mathrm{Na}$ primeira parte deste estudo vimos como muitos nomes eram motivados na sua origem, e que com o decorrer do tempo tornavam-se opacos. Na verdade, todas as línguas, em maior ou menor grau, têm palavras transparentes e opacas. Ullmann ${ }^{7}$ compara três línguas, francês, inglês e alemão, para demonstrar tal fato. As palavras opacas, também por ele chamadas convencionais, não demonstram claramente seu significado, exemplificativamente, luva: A forma inglesa glove ou a francesa gant não têm nenhum vestígio de seu significado em sua forma, ao passo que seu correspondente alemão é transparente, desde que se conheça o significado de seus dois elementos componentes: HandSchü, literalmente, sapato para as mãos (hand=mão; Schü=sapato). Um falante estrangeiro, por exemplo, poderia deduzir o conceito de luva da palavra alemã, mas necessitaria apreender conteúdo e expressão do mesmo vocábulo nas outras duas línguas (e por esta razão o autor emprega o termo convencional para designar a palavra opaca). Ullmann ressalta que já os gregos dividiam-se em duas correntes ideológicas quanto à motivação das palavras: havia os naturalistas, para quem as palavras possuíam o significado por natureza (jusei), em virtude da correspondência intrínseca entre som e sentido; e os convencionalistas, que concebiam a palavra como um "contrato social" (nusei).

Uma explicação para a ocorrência de muitas palavras opacas em determinadas línguas remete ao que houve na língua portuguesa durante o Renascimento: a substituição de formas transparentes por outras, clássicas, opacas, de significação apreensível unicamente por quem dominava as línguas clássicas. Criou-se, assim, o que

\footnotetext{
${ }^{7}$ A teoria de Ullmann aqui retomada foi retirada de duas obras do autor. Indicação completa nas referencias bibliográficas.
} 
Ullmann denomina "barreira lingüística", discriminatória, que corrobora para uma acentuação de desníveis socioculturais e econômicos.

Genericamente, há alguns tipos de motivação: a fonética, a semântica e a morfológica. O primeiro tipo refere-se às onomatopéias, o segundo refere-se à diversidade de sentidos, onde a decodificação depende do contexto: raiz, morfologicamente, é opaca; enquanto a raiz do mal é transparente, pois se trata de uma metáfora auto-explicativa. O terceiro e último tipo de motivação recobre palavras como automóvel, nas quais os formantes auto e móvel já significam, por si.

A motivação semântica, em particular, nos interessa. Dentro dela, podemos falar do processo de neologia, ainda que brevemente. Quando uma palavra já existente adquire um novo significado, pode ser considerado um neologismo. Alves (1990) cita, concretamente, o exemplo da famosa apresentadora de televisão que designa as crianças em geral como baixinhos. Na verdade, a apresentadora utilizou-se de um lexema já disponível no sistema lingüístico (que definia um adjetivo indicativo de altura), atualizando-o diferentemente: o conteúdo e a expressão baixinhos servem de expressão para um novo conteúdo (criança). Dependendo do contexto, os demais falantes compreendem se o emissor refere-se a baixinho como adjetivo ou como substantivo, em sua forma neológica.

Pretendemos, ainda, falar de outras duas condições de surgimento de neologismos: pode ser importado de outra língua e incorporado ao português integralmente (conteúdo e expressão referindo-se ao mesmo objeto, até então inédito na comunidade: certamente foi o caso de uísque, forma aportuguesada do inglês whisky, para designar uma bebida destilada proveniente da Escócia, onde se fala inglês), ou ainda existem neologismos surgidos de "experiências" dos falantes com a língua (como o "imexível" criado há alguns anos pelo então ministro Rogério Magri).

Examinando a primeira condição de surgimento de neologismos, percebemos que este processo é o que ocorre com antropônimos e ocasiona o esvaziamento semântico. Tomemos como exemplo um apelido originado em uma alcunha, Pinheiro. Para Leite de Vasconcelos, o fator de comparação entre o denominado e o objeto era a altura: João Pinheiro foi assim chamado por ser "alto como um pinheiro". Por este 
atributo físico, recebeu a alcunha, cujo sentido era percebido claramente (a alcunha era transparente): havia conotação, metáfora. Seus descendentes, contudo, não receberam toda a carga semântica contida na alcunha, pois já não havia relação entre objeto e denominado.

Portanto, quando um lexema como pinheiro, com conteúdo e expressão próprios (conteúdo=conceito: árvore da família das coníferas, procedente de regiões de clima temperado...; expressão: /pinheiro/), é utilizado para estabelecer comparações, a partir da atualização deste lexema o vocábulo adquire um novo sentido, sem perder seu sentido "primitivo": é como se o vocábulo fosse dividido em dois. Quando pela primeira vez o lexema é atualizado com referência a um novo objeto (ou seja, no ato da denominação), o conteúdo perde seus semas denotativos. Conteúdo e expressão de <pinheiro>, em função semiótica, passam a ser expressão de um novo conteúdo, conotativo, o Pinheiro alcunha (o esquema (ERC) RC de Barthes):

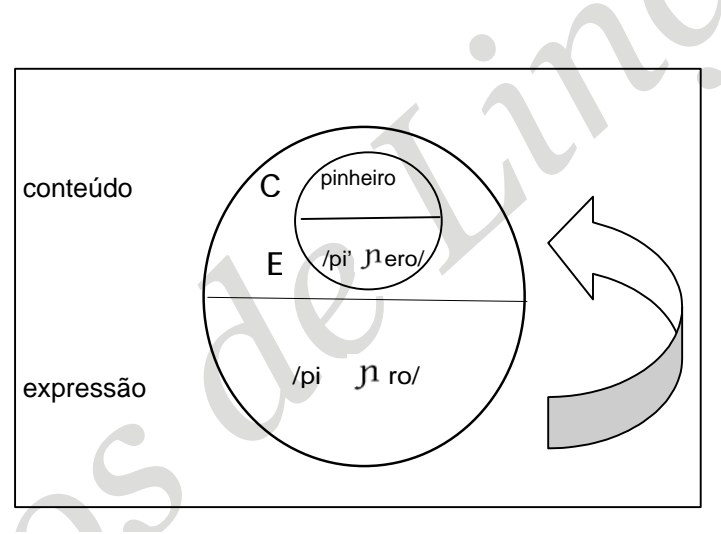

FIGURA 1: FUNCAO SEMIÓTICA (segundo o esquema de R. Barthes). A expressão da lexia pinheiro continua a mesma, embora haja duplo significado. A terminologia sígnea foi tomada de Hjelmslev: $\mathrm{C}=$ conteúdo (significado) e E= expressão (som). Representação da passagem semântica de pinheiro (objeto) a Pinheiro (apelido de família).

Essa é a explicação lingüística que se dá para demonstrar porque atualmente o nome na maior parte das vezes não é mais um significado, mas apenas um som no ato do batismo; principalmente quando nos referimos ao nome próprio de pessoa. Pesquisas realizadas periodicamente ${ }^{8}$, com informantes de faixas etárias e classes sociais variadas, vêm apurando que a maior motivação para a escolha de um nome é "a beleza do som”.

${ }^{8}$ As pesquisas às quais nos referimos são realizadas principalmente em nível de graduação no âmbito da disciplina Toponímia Geral e do Brasil, oferecida regularmente pelo Departamento de Letras Clássicas e Vernáculas da FFLCH-USP. 
Poucos são os que se interessam em saber que o nome significa, mas no fundo a ideologia que permeia a nomeação continua a mesma, pois o homenagear seu ídolo do futebol, da canção popular ou da televisão dando seu nome ao filho nada mais é que uma maneira de projetar na criança o desejo de sucesso alcançado pelo modelo portador do nome, assim como os visigodos - entre tantos outros povos antigos -, no século V, chamavam ao recém nascido "Richard" port. Ricardo, poderoso (Rich) e forte (hard).

\section{Conclusões}

Pelo que se discorreu ao longo deste estudo, apenas queremos sistematizar, neste espaço de reflexão, algo que já foi dito ao longo deste ensaio: que o nome de pessoa seja ele aplicado a uma pessoa a uma entidade que representa uma pessoa (como analisamos em artigo posteriormente publicado (Carvalhinhos, 2002), no qual trabalhamos com nomes próprios de personagens) - é um manancial rico para conhecimento não apenas da língua, mas também permite apreender um pouco da cultura, religião e até ideologia do povo que o criou em determinada época, uma vez que a língua mantém intactos nos nomes de pessoas as partículas mínimas de significação (semas), preservando os já mencionados aspectos ideológicos, de fé ou simplesmente contando a historia da denominação humana como vimos; aspectos que são passíveis de reconstituição por meio da ciência onomástica em sua vertente antroponímica.

Uma vez que em nossa sociedade (e, portanto, em nosso sistema onomástico) o nome próprio de pessoa assume o papel de uma etiqueta, pelo menos aparentemente, fica claro o que Dick (1990) aponta, no sentido de a Antroponímia ser composta por um inventário lexical mais ou menos fechado, em oposição à Toponímia, que é um inventário lexical aberto. Ou seja: a partir do momento que numa sociedade o nome perde sua função conotativa e passa a ser um identificador vazio de sentido, é provável que novos signos não sejam escolhidos no eixo paradigmático da linguagem para denominar pessoas, causando certa estranheza pessoas chamadas $\underline{\text { Mel }}, \underline{\text { Amora }}, \underline{\text { Flor, }} \underline{\text { Sol }}$ ou Lua; embora seja uma escolha lícita do ponto de vista linguiístico, pode parecer menos adequado do ponto de vista social, uma vez que estamos acostumados a encarar substantivos como estes apenas como comuns, e não próprios. 
Portanto, acreditamos que pudemos esclarecer neste espaço que o nome é muito mais que um mero identificador ou uma etiqueta, é antes um vasto campo de estudo e um convite a entender as sociedades que o geraram, numa perspectiva diacrônica, e as que o utilizam, em perspectiva sincrônica. 


\section{REFERÊNCIAS BIBLIOGRÁFICAS}

ALVES, Ieda Maria. Neologismo - criação lexical, São Paulo: Ed. Ática, 1990.

BARTHES, R. Elementos de Semiologia, trad. Izidoro Blikstein, São Paulo, Cultrix: 1972.

BRÉAL, Michel. Ensaio de Semântica, trad. Aída Ferras et. Al. São Paulo: EducPontes, 1992.

CARVALHINHOS, Patricia de J. Antroponímia: Um velho caminho, um novo instrumental de análise lingüístico-literária. Revista Álvares Penteado, São Paulo, v. 4, n. 8, p. 115-135, 2002.

COSERIU, E. Teoría del lenguaje y lingüística general. Madrid, Gredos: 1969.

DICK, Maria Vicentina de P. do A. Toponímia e Antroponímia no Brasil: coletânea de estudos, São Paulo: FFLCH, 1990.

GUÉRIOS, R.F. Mansur. Dicionário etimológico de nomes e sobrenomes, $2^{\mathrm{a}}$ edição revista e ampliada, São Paulo: Ed. Ave Maria, 1973.

HJELMSLEV, L. Prolegomènes à une théorie du langage. Paris, Minuit: 1971.

PAIS, Cidmar Teodoro. Ensaios semiótico-lingüísticos, 2a edição, São Paulo: Global Editora, 1984.

POTTIER, B. "Os esquemas lingüísticos”, Lingüística geral: teoria e descrição, tradução e adaptação portuguesa de Walmirio Macedo. Rio de Janeiro, R.J.: Presença: Universidade Santa Úrsula, 1978.

ULLMANN, Stephen. Semântica. Uma introdução à ciência do significado, $2^{a}$ edição, Lisboa: Fundação Calouste-Gulbenkian, 1964.

VASCONCELOS, José Leite de. Antroponímia Portuguesa, Lisboa: Imprensa Nacional, 1928.

_opúsculos, V. III, Coimbra: Imprensa da Universidade de Coimbra, 1931. 